\title{
Response to: a stepwise cesarean section for placenta percreta: effective only for "separable" placenta percreta?
}

\author{
Ahmed Shabana $\cdot$ Muhammad Fawzy • \\ Waleed Refaie
}

Published online: 12 November 2014

(c) Springer-Verlag Berlin Heidelberg 2014

Thank you for your response [1] to our manuscript [2].

Mansoura stepwise approach in placenta percreta management is a novel approach to preserve the uterus as possible and change in the concept of Placenta percreta management always mandates hysterectomy.

Placenta percreta is morbidly adherent placenta (not separable) and if it is separable there was no need for stepwise approach to decrease bleeding (intraoperative or postoperative) and morbidity in the study as bladder resection or injury (table 3 ).

With strong uterine contractions, placenta "percreta" not spontaneously separated or removed, early combined ecbolics (strong uterine contraction) to minimize blood loss and help manual removal of placenta adherent to uterine wall.

All patients included in the study were placenta percreta, other types (accrete, increta) excluded from the study. Diagnosis confirmed by Doppler and MRI after early detection by ultrasound during pregnancy. Experienced obstetrician can distinguish intraoperative between accreta and percreta.
In this study we highlight the necessity of experienced teamwork (obstetrician, anesthetist and assistant), preoperative blood and fluids preparation, control uterine blood loss (uterine incision, blood vessels) and proper identification of lower uterine segment and repair. With confirmation of steps included in the study to preserve the uterus in placenta percreta (table 2), we should also confirm the possibility of supracervical hysterectomy when repair revealed functionless uterus and life threatening intraoperative hemorrhage.

\section{References}

1. Matsubara S (2014) A stepwise cesarean section for placenta percreta: effective only for "separable" placenta percreta? Arch Gynecol Obstet. doi:10.1007/s00404-014-3542-8

2. Shabana A, Fawzy M, Refaie W (2014) Conservative management of placenta percreta: a stepwise approach. Arch Gynecol Obstet. doi:10.1007/s00404-014-3496-x

This reply refers to the comment available at doi:10.1007/s00404-014-3542-8.

\footnotetext{
A. Shabana $\cdot$ M. Fawzy $(\bowtie) \cdot$ W. Refaie

Department of Obstetrics and Gynecology, Faculty of Medicine,

Mansoura University Hospital, Mansoura, Egypt

e-mail: mmfawzy@hotmail.com
} 